\title{
Comparative Research of Attitudes to Mediation at Galician and Siberian Universities
}

\author{
Julia V. Popovaa ${ }^{a}$ Artem A. Smolyaninova \\ and Maria del Mar Lorenzo Moledo ${ }^{b}$ \\ ${ }^{a}$ Siberian Federal University \\ Krasnoyarsk, Russian Federation \\ ${ }^{b}$ University of Santiago de Compostela \\ Santiago de Compostela, Spain
}

Received 16.09.2020, received in revised form 23.09.2020, accepted 10.12.2020

\begin{abstract}
The article presents the conceptual ideas of implementing mediation in higher education of Spain in comparison with the Russian practices. It describes mediation in education in terms of its evolution, general and specific models, its resources in the development of professional competence of university staff. Authors discuss the didactic potential of mediation in higher education in the two countries. The article considers the empirical data obtained in simultaneously conducted research at Galician and Siberian universities for comparative analysis of the specific features and the methods implemented in Spain and Russia. It reveals the higher education staff awareness, attitudes and readiness to perform mediation techniques and its relevance in their professional activity.
\end{abstract}

Keywords: conflicts in education, mediation, university environment, mediation service, teacher training.

The research sponsored by the Russian Foundation for Basic Research (RFFR). No. 18013-00528 "The study of mediation practices in the field of education for harmonization of interethnic relations in a multicultural environment".

Research area: pedagogy.

Citation: Popova, Ju.V., Smolyaninov, A.A., Lorenzo Moledo, M.M. (2020). Comparative research of attitudes to mediation at Galician and Siberian Universities. J. Sib. Fed. Univ. Humanit. Soc. Sci., 13(12), 1962-1972. DOI: 10.17516/1997-1370-0697.

(C) Siberian Federal University. All rights reserved

* Corresponding author E-mail address: julia.popova@inbox.ru, smolartem2004@mail.ru, mdelmar.lorenzo@usc.es ORCID: 0000-0001-7321-7102 (Popova); 0000-0002-2768-3329 (Lorenzo Moledo) 


\section{Introduction}

The challenges of education in the current moment address to the enormous pedagogical potential of mediation. As an educational method, mediation in education is aimed at the promotion of the culture of peace through awareness-raising, constructive discussion, understanding the position of the other party. These days, training in conflict management, tolerant outlook, empathy and mediation becomes especially relevant for educators. The positive management of the conflict requires the use of certain skills, procedures and techniques. It is achieved only with the clear and determined support of the public administrations who are competent to provide the methodological resources and teaching materials that are necessary for the training of future experts - "train the trainers" - and for the establishment of mediation services in educational institutions.

Among the popular models of mediation in global knowledge, such as restorative model, the transformative mediation model and others, Spain is famous with the narrative mediation model disseminated by Sara Cobb. It is both an approach and a methodology, providing mediators with a way of incorporating stories into the very fabric of mediation. Thus, the procedure of mediation becomes a storytelling process which is both informative and psychologically therapeutical. “... telling one's story in mediation serves simultaneously the ethical mandate, "participation", as well as the pragmatic mandate to move "from story to settlement" (in Toran Hansen, 2003). Narrative Mediation builds on the storytelling metaphor, encouraging which is a unique skill of a mediator. There is no "one truth" to discover, but there are individual interpretations of what has happened. The conflict parties pass through three stages: engagement into the mediation process, deconstructing the conflict saturated story, and constructing an alternative story. Face-to-face contact between participants is maximized during the sessions. The parties attempt to uncover underlying issues and the hidden interests. An effective mediation procedure offers participants to describe the conflict, reflect on it from different points of view and identify positions, options and possible solutions. The key is being transferred by the catchphrase of Michael White's for the Narrative Therapy: "the people are not the problem; the problem is the problem" (in White, 2000). The goal is not simply to reach agreements but to use the intervention as an opportunity to improve communication and to develop a foundation for addressing problems in general.

For that, mediators increase understanding among the disputants by relying on their will to overcome relationship problems. Undoubtedly, the mediator's personality is an important aspect of the mediation process and can be considered as the main tool, where individual components and characteristics of the individual, together with mediation technology, play an integral role. "The values, beliefs, abilities, attitudes, level of competence and other qualities of a specialist form the basis on which the skill of a mediator grows". In the mediation process, mediators apply a series of skills and competencies: active listening, empathy, nonverbal language, structure of negotiation, etc. Those skills and competencies are built and developed during a training course or university program, and later on as a continuous professional development of a mediator.

\section{Mediation in Russian education system}

In Russia, after the release of the Federal Law on Mediation dated 27.07.2010 No 193-FZ and the Letter of Ministry of Education and Science of the Russian Federation dated 18.11.2013 No VK-844/07 "The Guidelines for the Organization of School Mediation Services", secondary schools began to create reconciliation services and mediation centres. Their main purpose was the introduction of innovative methods of dispute resolution and preventing conflicts between all actors of the educational process. At the moment, almost all Siberian schools reported on holding mediation services. On the other hand, pre-school organizations, vocational schools, colleges and universities do not usually establish such services. As a rule, the school mediation service employs mediators and supervisors of the reconciliation service: a teacher or a psychologist who came through special training; and school students 
who wish to learn the mediation approach to solving problems and practice it (peer-mediators).

Russian scientists (A. Konovalov, A.Chupris and others) describe several models of mediation in the education of Russia: restorative (problem-solving or settlement-directed) mediation; transformative mediation; narrative mediation; evaluative mediation. Some Western models: community mediation, ecosystem or family-focused mediation and others are not mentioned in Russian educational practice. Application of these models in various educational institutions entails significant differences in the goals and objectives of mediation, as well as in the functions of a mediator. The most common in educational institutions of Russia is restorative mediation. It focuses on the interests of all participants in a conflict or problem situation (students, their parents, teachers, management, etc.). In this approach, the teacher-mediator should take a neutral position and help the conflict parties to recognize the harm being caused and suffered, to understand that the opponents have common interests and needs, and focus on finding solutions that satisfy all parties.

The formation and development of the methodology and practice of training mediators in education is being in the initial phase of implementation. Training of mediators for the education system in Russia includes academic courses in higher education (mainly at the Master's level) or programs of professional development of teachers, psychologists and social services specialists. For instance, the Master's program Mediation in Education at Siberian Federal University includes the following modules: methodological, managerial, legislative, instrumental, communicative modules, internship and research work. The internships are organized to provide supervised sessions, introducing professional activities at school services of reconciliation and mediation centres. Among the main training methods, there are: fieldwork, problem learning, case studies, role-plays, modelling, active training, supervision. However, despite the efforts of a number of universities to deploy a system of Master's programs, in Russia mediators are commonly trained at courses offered by licensed educa- tional centres. Retraining or refresher courses on Mediation for educators are short (36-72 hours) and allow gaining skills in mediation procedures and further working at school reconciliation services because it was the obligation to fulfil.

The didactic models for training mediators in Russia and Spain are similar. The skills to be trained for the profession of educational mediators are consistent with the principles of mediation: voluntariness, confidentiality, cooperation and equality of the parties, impartiality and independence of the mediator. They form the mediation competence of a modern education worker, including teachers, administrative staff and others. V. Semikin defines mediation competence as the ability to skilfully build interactions and to solve the difficulties by realizing and controlling the situation. We understand the mediation competence of a teacher as an integrative property of a person which characterizes readiness to carry out constructive negotiations between the conflicting parties in a neutral position and ability to implement mediation techniques within the professional activity. We distinguish the following structure: cognitive, motivational-value, activity and reflexive aspects of this competence. Training mediators for the achievement of the planned educational outcomes include active, practice-oriented forms (role-playing games, workshops, interactive lectures, case studies, viewing and analysis of video cases, supervision, etc.). No less important are the theoretical knowledge, such as the legal basis of mediation in education, fundamentals of psychology, culture of interpersonal communication, conflict studies. The problem is that the current offer of teaching courses does not match these requirements and many mediators at school do not use the pedagogical potential of mediation, choosing the authoritative approach of conflict management.

\section{Mediation in higher education of Spain}

The gradual implementation of mediation into Spanish university life has been promoted by the Organic Law on Universities (LOU, 2001). It attempts to incorporate students into 
the status of the protagonists of their learning process, assuming their decision-making in conflict resolution. It is reflected in the definition of mediation in education developed at the University of Seville and Pablo de Olavide University. They define mediation as a non-competitive negotiation of two or more people (or entities) assisted by a third party trained in specific techniques for that task acting as a mediator. The mediator helps those involved to visualize, identify and clarify the conflict, and generate alternatives and options to reach an acceptable solution to finally put their agreements in writing. The mediator uses certain skills, techniques and/or strategies for which prior training is required. Another aspect that is crucial in the concept of mediation is the introduction of the conflict understood in its broader concept, not only as a negative but also as a factor of personal or institutional evolution. Conflict resolution or management is based on the idea that everyone wins and no one loses.

There are Universities that establish mediation services or alike bodies, for example:

- The Department for Mediation and Conflict Counselling of the University of La Laguna (La Unidad de Mediación y Asesoramiento de Conflictos, UNIMAC).

- The Service of Attention to the University Community of the University of Huelva (SACU).

- The Mediation Group of the Carlos III University of Madrid (UC3M).

- The University Centre for Conflict Transformation of the University of the Basque Country (GEUZ).

- The Comprehensive Centre for Conflict Analysis and Resolution of the University of Santiago de Compostela (CIARCUS).

The latter was created in 2013 as a multidisciplinary Research Centre in conflict management and resolution, both through traditional and alternative ways. Its primary objective is the promotion of study, development and dissemination of knowledge in this field, as well as gathering the material for students' training based on real case studies. CIARCUS consists of two different sections, Legal Study and Mediation Centre.
CIARCUS Mediation Centre claims the following objectives:

- Promote scientific study and research on aspects related to mediation.

- Offer citizens and, in particular, the university community access to mediation as a tool for conflict prevention and management.

- Undertake training activities in mediation and alternative conflict management, both those that are promoted or commissioned by the USC and by external promoters.

- Establish collaboration agreements with other regional, national or international organizations with convergent objectives with the Centre.

- Promote the dissemination of mediation and the culture of peace among wider audience.

Alone with it, the Legal Study, comprised of the professors from the USC Faculty of Law, provides counselling, performs legal defences, accredits the preparation of reports. The entire body is aimed at channelling the research initiatives of university teachers and the transfer of the results of their research.

Universities exchange their experience of mediation and conflict management through conferences and Mediation centre associations such as Defensor Universitario in Madrid. The University Conference for the Study of Mediation and Conflict (CUEMYC) are being hold regularly. The Association was created in 2012 by the Directors and Heads of Postgraduate Studies and Research Groups and Institutes of 50 universities in Spain and other countries.

The objectives of these non-profit educational bodies and associations are the following:

- Promote the development of Mediation and Conflict Management as a cooperative, constructive and peaceful way to address personal conflicts and as a safeguard of the general interest.

- Develop the necessary actions so that the professional activity of mediation is regulated and recognized in all its areas.

- Guarantee the proper training of mediators and recognition of the role of these professionals. For this purpose, a catalogue of es- 
sential skills is being developed for the training of Mediation and Conflict Management professionals, approaching European and international standards in this matter.

- Establish a system of mutual accreditation of training programmes among universities in this area and facilitating student exchanges where appropriate.

- Propose improving students' personal, social and academic performance.

- Organize systems for the promotion and exchange of knowledge in mediation through specialized publications, events and other ways of dissemination.

- Foster research related to conflicts, cooperative and constructive conflict resolution, mediation, management and transformation of conflicts and coexistence.

- Establish the institutional and individual relations, nationally and internationally.

It can be concluded that mediation in the education system of Spain is widely spread at the university level. Higher education takes on the advantage of constructive and peaceful resolution of conflicts for creating a safe education environment. It's also contributing to the academic knowledge and expertise by studying mediation, analysing cases, collecting data for research. Consequently, along with the collaboration it provides government bodies and practitioners with tools and resources for the prevention of violence and the improvement of coexistence in learning centres. All of these foster promotion and development of mediation among young people and wider audience (families, colleagues, friends) achieving maximum progress and proven results.

\section{Methods}

The theoretical study of mediation in the education of Spain in comparison with Russian practices stipulated the search for a scientific problem: How popular is mediation in education from the perspective of the University staff? The aim of the survey was to evaluate awareness, attitudes and readiness to perform mediation among the respondents from two countries. The two University staff cohorts did not have a significant difference in their status and experience, therefore there were unified survey tools elaborated and translated in two languages and implemented in each, to achieve the research goal.

The questionnaire was completed and published online; the outcomes were processed automatically. We set out to investigate the following issues:

- If there are any conflicts in the university environment and if they are connected with cross-cultural issues.

- If professors, administrators and researchers are aware, experienced and ready to implement mediation in educational sphere.

- What they think of the mediation competence relevance for teachers.

- If they would like to contribute to improving their skills in mediation.

The Spanish group of respondents were professors, researchers, administrative and other staff of University of Santiago de Compostela (USC) in Galicia working in the Pedagogy and Didactics Department and research group ESCULCA. In total, 40 University employees took part in the online survey. Among them, women $(70 \%)$ outnumbered men $(30 \%)$. Almost half of the participants were aged over 45 (49\%); 20\% were aged between 36 and 45 and $31 \%$ were $25-34$ years old. At the same time, the similar survey was conducted in Russian language for the staff of Siberian Federal University, city of Krasnoyarsk, Russia. The sample was representative with respect to Spanish cohort in gender, age, scientific title, position, field of study and job experience. The interviewed were mostly staff of the School of Education, Psychology and Sociology. Russian respondents were aged between 26-35 (7\%), $36-45(33 \%)$ and over $46(60 \%)$. Professors were $93 \%$ of the cohort.

The positions of Spanish staff were as follows: professors $-70 \%$, researchers $-16 \%$, administration and other categories $-14 \%$. It is explained by the fact that some respondents have dual posts and they chose the primary activity as their major position. Less than $10 \%$ of the Spanish research group had Master's and Bachelor's degrees. One quarter identified their education level as "PhD in progress" and the majority of respondents $(67 \%)$ had a $\mathrm{PhD}$ degree majoring in Education Science (92\%). 
Also, Biology and Psychology fields of study were mentioned.

As for Russian staff, they mostly had $\mathrm{PhD}$ (Candidate of Sciences) degree (80\%) in Education, Psychology, Humanities and other fields (Physic and Mathematics, Urban Construction). It compounds a correct stratum of the target audience to study the issue. The average working experience of the Spanish respondents was 12 years, with 4 people having no experience, but one third having seniority of over 20 years. In the Russian cohort, professors were with the experience of 7 to 43 years, in average 20 years.

We suppose that the sample was representative for the survey with respect to the gender and the experience to conduct the comparative analysis of the obtained results.

\section{Results}

Both in Spain and Russia, the interviewees were aware of mediation and could give their judgments on its relevance and effectiveness. Among those Spanish educationalists who replied, $43 \%$ had taken courses or classes on conflict management in education. Accordingly, $57 \%$ reported that they had never had training in a field of mediation. We suppose that the gap in the respondents' experience is caused by a change in the teacher training paradigm. As for the Siberian Federal University staff, there were more people who had been trained in the field. In the recent years, the School of Education, Psychology and Sociology immersed in the topic of mediation in education. University professors participated in refresher courses and educational programs, invited visiting professors from Europe and other Russian regions. There were retraining programs for the employees given by professional mediators. As a result, an annual International Youth summer school Mediation in Education has been held since 2017. In 2018, the admission to the Master's program Mediation in Education was begun to train professional mediators for the education system of Siberia, Russia. Therefore, mediation as a professional activity and an educational technique is well known at the Siberian University.

Answering the question aimed at evaluation of awareness, only $5 \%$ of Spanish educa- tionalists pointed out that they were not familiar with mediation for resolution of conflicts in education. One half knew it in general and $45 \%$ knew the principles and objectives, types and procedures of mediation in education. Among the Russian cohort, there was no one unfamiliar with mediation in education. $32 \%$ knew it in general terms and the rest $68 \%$ knew in depth. It is explained by the training in mediation mentioned above.

The absolute majority (94\% in Spain and 90 in Russia) consider mediation competence to be necessary for a teacher/professor. This reveals the comprehensive attitude and recognition of the advantages of mediation in education. It is especially important in the current conditions when the need to the person-oriented, tolerant, humanistic methods in education is so high.

In order to identify the relevance and demand for mediation in conflict resolution in the educational environment, the participants were asked: "Do you think that the threat of conflicts among students, teachers and the administration is very serious, rather serious, rather small, very small?" The answers indicate a sound and safe situation in Spanish education. USC staff mostly felt that conflicts were less possible $(67 \%)$ or not possible $(18 \%)$ in the educational centre. Only $15 \%$ answered that the threat was serious. At the same time, Russian respondents had different opinions. $40 \%$ evaluated the threat of conflicts as minor ( $7 \%$ not possible, $33 \%$ less possible), but almost one half thought conflicts were a rather serious $(47 \%)$ and serious (13\%) threat. The roots of such attitudes might lie in a number of concepts. The first issue is understanding the term Conflict in education, which might be perceived as both an argument or even a scandal in an educational environment. For others, a conflict is any mismatch of positions, a failure in meeting personal goals and interests. So, conflicts might be perceived and reflected at various stages of escalation and it requires a further research analysis.

The next questions were about the measures taken by the state and municipal authorities and also by the university to combat conflicts. Interestingly, the majority of educationalists both in Spain and in Russia sup- 
pose the measures to be insufficient both on the national and institutional levels (equally appx.70\%). Therefore, personal involvement and participation in social actions, scientific projects, self-regulating bodies are so important in educational environment. Especially professors who have knowledge and expertise should maintain promotion of constructive conflict management and make profit on their influence on young people.

Answering the next question, only two Spanish educationalists pointed the question as Not Applicable which can result from unawareness. The majority of the respondents $(94 \%$ in Spain and $92 \%$ in Russia) agreed that mediation allowed students to resolve and prevent conflicts in their learning. So, we realize that higher education workers suggest mediation a sufficient tool for conflicts resolution.

Another important finding was that answers to "Have you been engaged in or observed a conflict in education during your work?" were 60\% negative in Spain and 53\% negative in Russia. So, in both countries, less than a half of the University staff encountered conflict situations in the educational environment. This result might be interpreted as very comfortable conditions and a peaceful interaction between students and friendly cooperation with professors. Alternatively, conflicts might be latent and hidden so that the stress and inner tension do not find the way out and opportunity to be improved. The specifying questions allowed to define the parties. According to the answers, $28 \%$ of conflicts occurred between students, 24\% involved students and teachers and the same share - staff/institution conflicts. Also, 19\% of conflicts occurred between students and the administrative staff.

The situation at the Russian University was quite different. The majority of conflicts arose between students and professors (64\%), between professors and administration $-22 \%$, between students and administration $-7 \%$, and also $7 \%$ were other conflicts. This might be caused by Russian professors' focus on their conflicts and unawareness of problems and disputes among students. Therefore, Russian educationalists only counted the conflicts they were involved in. As a rule, conflicts between students are usually not demonstrated in the classrooms. Spanish people are believed to be more temperamental and emotional compared to Siberians, who prefer retaining and reserving their personal problems.

According to the survey, 53\% of Spanish respondents did not ask for any help of support in the education-related conflicts. Among those who applied for assistance, $70 \%$ were institutional administration and 30\% were specialists (mediators or psychologists). In Russia, the request for support is amazingly small, only $13 \%$ applied for help; among them, 92\% asked for administrative support and only $17 \%$ sought specialized assistance. This result points out the lack of popularity of mediation and psychological services in Russian education system, their availability and perhaps other reasons of avoiding specialized services. There might be both unawareness and conservatism of Russians. Russian actors of education prefer seeking administrative resolution from the seniors, management and authority bodies. It is a traditional misconception to evade responsibility and escape the consequences of dealing with the conflict autonomously. So, Russian staff addresses the resolution of conflicts to their chiefs with the illusion of fast and complete decision, but later they might realize the shortcomings of authoritative decisions and suffer from incomplete and uncooperative solutions.

To clarify the roots of conflict situations, and especially to find out if there were any intercultural issues, two items were added to the questionnaire. Surprisingly, only a half of the respondents in Spain reported that they had some multicultural student groups with representatives of different nations, ethnicities, cultures. The negative answer of the other $49 \%$ was somewhat counterintuitive. The share of those having multicultural student groups in Russia was higher $(80 \%)$. Besides, the question of the conflicts observed by university staff and their relation to the cultural differences collected a certain negative response. Only one person in Spain answered positively. In Russia, the diversity of cultures caused educational conflicts in $20 \%$ of cases, according to the interviewed. We are glad to find out about the peaceful coexistence of diverse cultures in the educational en- 
vironment due to ethnic tolerance, intercultural dialogue and mutual respect in the humanistic and individual-oriented paradigm of learning.

In the final part of the survey, respondents were asked three questions revealing their readiness to learn and apply mediation techniques in their work and social actions. The answer about the willingness to apply for mediation service for education-related conflict settlement was responded by interviewees in a positive way. Only $3 \%$ of Spanish educationalists replied they were not willing to, $11 \%$ claimed they would like to learn and practice mediation for family and social issues. The majority of those surveyed (86\%) answered that mediation was relevant to be studied and implemented for social and professional activities. As for the readiness to apply mediation in education for conflict management, the replies divided precisely into two opposite groups: one half of the respondents supposed themselves to be ready, and the same number didn't think they were. It can be a result of learning and working experience as well as the training in conflict studies, dispute management and mediation.

As for the Russian education staff, the results were approximately the same, with a minor fluctuation in numbers and shares. Almost all staff were both willing and ready to implement mediation, mostly for professional activities. May be because of the larger overall experience and also an opportunity to be involved in teaching, supervision and mentoring Master's students of the Mediation in Education program, a larger share of professors were ready to implement mediation $(76 \%)$. The popularity of mediation as a method of alternative dispute resolution (ADR) is explained by the advantages of a more flexible and informal form of negotiations and the higher probability of reaching a sufficient solution.

\section{Conclusions}

It can be concluded that Spanish higher education has been institutionally committed to the extension and consolidation of mediation in the learning environment. In recent decades, a number of initiatives have been developed to promote mediation. A vast majority of educational institutions have mediation services that could be used by the actors of education: teachers, students, parents, technical and administrative staff. In Spain they are called "servicios de mediación, concilacion, reparación intrajudicial y extrajudicial", which implies reconciliation services or harm reparation cabinets at schools and universities that foster the use of mediation techniques. In the University of Santiago de Compostela, there is the Comprehensive Centre for Conflict Analysis and Resolution (CIARCUS) established, but not all the actors of the learning process take advantage on it.

We monitor and evaluate the readiness of the Russian education system to implement and popularize the mediation approach, including higher education level. On the example of Siberian Federal University, the establishment of the Centre for Mediation in Education and Social Sphere at the School of Education, Psychology and Sociology should be highlighted. It is in addition to the other Mediation Centre which was created 10 years ago in the Law School of SibFU. The Master's program on training mediators for education was launched in 2018. Mediation is being introduced in the curricula of Teacher training and Tutor's Bachelor's programs for equipping young specialists of education with the techniques of conflicts prevention and resolutions. The annual International Summer Schools on mediation were held since 2017 and an International Conferences, round tables, seminars and refresher courses to promote mediation for professors and wider audience are being conducted regularly.

The empirical analysis of data collected in the online survey of the university staff in the two countries draws a number of conclusions. Interviewing teachers and other categories of the university staff, we found out that the staff of the average 12-20 years' experience in teaching faced conflicts in less than half of all cases $(40 \%)$. On the higher education level, conflicts are not so widely spread or do not always escalate to the collision or dispute phase from the hidden tension state compared to secondary school. As we understand, there might be non-perceived conflicts and latent conflicts, or that are perceived but not desired to be developed by the actors of education. Such issues as 
non-flexible schedule, problems in the curricula completion, administrative and regulatory pressure, mismatch in teaching and learning styles, heavy workload are often not seen by researchers and professors as conflict triggers, but no doubt they are. All the arising problems might have been aired and defined, constructively negotiated and resolved quickly and effectively, unless that the staff didn't perceive the situation to be a conflict. The pedagogical concern is in the impact where conflicts and disputes are not likely to take place, according to the educationalists. Alternatively, these responses relating to conflicts might have been subjective and were therefore susceptible to recall bias.

Also, all the respondents almost unanimously decided that the possibility of conflicts in higher education is not high. It allows us to conclude that altogether: the work conditions, students' motivation and involvement, administrative support, teaching hours, opportunities to personal and scientific development are significantly favourable in the university. To clarify and resolve these issues striving for a safe and comfortable learning and teaching process, the education actors need some knowledge in conflict studies, management and mediation. These conclusions are subjective and are not supported by any data because a deliberate additional research is needed to clarify the roots of the issue.

It is especially true for another surprising result of the survey, when the Spanish University staff indicated the student groups they worked for as multicultural in only one half of the cases. It is known that these days academic mobility is wide spread, and we can rely on the data provided by the International Relations Office of the University of Santiago de Compostela (ORE) (2020). According to the ORE, in the 2018-19 academic year, 1,840 students took part in the USC's mobility programs. 1,142 exchange agreements were signed with 453 universities from 31 European countries. Bilateral programs with countries outside the European Union allowed 419 students to join USC. It means that USC is a multicultural university with a brilliant intercultural policy. At the Russian university, the rate of multicultural student groups is $80 \%$ which is rather reasonable according to the international policy and mobility flows of SibFU. Apart from that, the staff could address not only to the diversity of ethnicities and nationalities, but also to the diversity of sub-cultures represented by students.

We consider the awareness and the understanding of advantages of mediation in education to be significantly high. It confirms the hypothesis that both Spain and Russia have a well-developed system of mediation in education and social sphere. Alone with being informed, and, in a number of cases, trained in the field, the professors, researchers and administrators of the two universities are mainly willing and ready to use mediation in their professional educational activity. It might cause a need for designing a refresher course or an additional educational program for the university staff, especially young professionals in the start of their career. It was derived from the survey outcome analysis, that young teachers with working experience under 5 years express willingness but lack conflict resolution skills to implement mediation in the classroom. It reveals the need of young teachers for professional development which can be achieved with the support of local authorities and educational centres to contribute to the quality of higher education in the region. With the other local (Russian, Siberian) data for comparative analysis, it becomes possible to evaluate the quantitative and qualitative outcomes of the research and to establish the foundation for further surveys and collaboration.

\section{Discussion}

The present research discovered that the participants of the higher education process are willing to learn and to contribute to the university ecosystem, which complies with the findings of the recent academic publications. Fostering intergroup knowledge might be a key to building "fair learning communities". Following the trendy lifelong learning approach, professors and other university employees express the need for developing the mediation skill as one of the core competencies of a modern teacher. It is a strong evidence of deliberate and full execution of decrees on the rights 
and duties of students and coexisting plans that are being implemented on the legislative level. Nevertheless, the majority of respondents of the survey consider the national, regional and institutional measures that seek to promote the dialogue and well-being to be insufficient. It therefore highlights the importance of conflict prevention in ensuring the favourable function- ing of any educational centre. It might need to involve more reflection on feelings, ideas and opinions to introduce and eventually develop the roadmap within an educational centre to benefit from it. Further data collection is required to determine exactly how mediation in education can be used for building mediation competence of higher education staff.

\section{References}

ASEMED - Spanish Mediation Association of the Ministry of Justice (2020). Available at: https:// www.asemed.org/

BIPC - Barcelona International Peace Centre (2020). Available at: https://bcnpeacecenter.org/

CIARCUS - Comprehensive Centre for Conflict Analysis and Resolution of the University of Santiago de Compostela (2020). Available at: https://www.usc.gal/es/institutos/ciarcus/

Cobb, Sara (2013). Narrative "Braiding” and the Role of Public Officials in Transforming the Public's Conflicts. In Narrative and Conflict: Explorations in Theory and Practice. 1. 10.13021/G8TG65.

Decree 8/2015 that develops the Law 4/2011 on the educational community in the matter of school coexistence and participation. Available at: https://www.xunta.gal/dog/Publicados/2015/20150127/AnuncioG0164-220115-0001 gl.html

Directive 2008/52/EC of the European Parliament and of the Council of 21 May 2008 on certain aspects of mediation in civil and commercial matters. Available at: http://data.europa.eu/eli/dir/2008/52/oj

ESCULCA - Investigation group at Faculty of Education Science of the University of Santiago de Compostela. Available at: https://www.usc.es/esculca/

Federal Law of 27.07.2010 No. 193-FZ “On alternative dispute settlement procedure with the participation of a mediator (mediation procedure)" (2010). Available at: http://www.consultant.ru

Grau, S., Gómez, C.G., Álvarez Teruel, J.D. (2016). La Mediación Universitaria: Un Recurso De Orientación. Experiencia En La Universidad De Alicante [University Mediation: A Resource for Guidance. Experience at the University of Alicante]. Available at: https://rua.ua.es/dspace/bitstream/10045/56608/1/2016_ Grau etal INFAD.pdf

Law 14/2007, International Catalan Institute for Peace. Available at: http://icip.gencat.cat/web/.content/ continguts/linstitut/documentaci_institucional/1lei_14/1lei_1407_ang.pdf

Organic Law on Universities 6/2001 (Ley Orgánica 6/2001 de Universidades (LOU) Available at: https://noticias.juridicas.com/base datos/Admin/lo6-2001.html

Smolyaninova, O.G. (2019). Training Model of School Intercultural Mediators Master's Program at Siberian Federal University, In: INTED2019 Proceedings, Valencia, 1991-1997

Smolyaninova, O.G. \& Popova, J.V. (2019). Specific Issues of Training Intercultural Mediators for Education in Europe and Russia. In: Journal of Siberian Federal University, 12 (2), 247-260.

Shamlikashvili, Ts.A., Hazanova, M.A. (2014). Metod 'Shkol'naia Mediatsiia' kak sposob sozdaniia bezopasnogo prostranstva i ego psikhologicheskie mekhanizmy [School Mediation Method as a Way of Building Save Environment and its Psychological Mechanisms]. In Psikhologicheskaia nauka i obrazovanie [Psychological Science and Education], 2, 26-33.

Toran Hansen (2003). The Narrative Approach to Mediation. Available at: https://www.mediate.com/ articles/hansenT.cfm

Taylor, Alison (2002). The Handbook of Family Dispute Resolution: Mediation Theory and Practice. San Francisco: Jossey-Bass. Available at: https://www.adr.gov/approach_mediation.pdf

The university mediation: a Resource Guide. Experience at the University of Alicante (2016). Available at: https://rua.ua.es/dspace/bitstream/10045/56608/1/2016_Grau_etal_INFAD.pdf

University Conference for the Study of Mediation and Conflict. Available at: https://cuemyc.org/en/ 
USC in figures: students in mobility programmes. Available at: https://www.usc.gal/es/usc/en-cifras/ movilidade

White, M. (2000). Narrative Means to Therapeutic Ends; Maps of Narrative Practice; Reflections on Narrative Practice Adelaide, South Australia: Dulwich Centre Publications

\title{
Сравнительные исследования отношения к медиации в университетах Галиции и Сибири
}

\author{
Ю.В. Попова ${ }^{a}$, А.А. Смолянинов ${ }^{a}$, \\ М.М. Лоренцо Моледо ${ }^{6}$ \\ ${ }^{a}$ Сибирский федеральный университет \\ Российская Федерачия, Красноярск \\ ${ }^{6}$ Университет Сантьяго-де-Компостела \\ Испания, Сантьяго-де-Компостела
}

\begin{abstract}
Аннотация. Авторы описывают особенности внедрения медиации в систему высшего образования Испании и России. Медиация в образовании рассматривается с точки зрения ее становления, общих и специфических моделей, ее ресурсов и дидактического потенциала в развитии профессиональной компетентности сотрудников вуза. В статье анализируются эмпирические данные, полученные в ходе сравнительных исследований в университете Сантьяго-де-Компостела и в Сибирском федеральном университете.
\end{abstract}

Ключевые слова: конфликты в образовании, медиация, университетская среда, служба примирения, подготовка преподавателей.

Исследование проводится при финансовой поддержке Российского фонда фундаментальных исследований в рамках научного проекта № 18-013-00528 «Исследование медиативных практик в сфере образования для гармонизации межнациональных отношений в поликультурной среде».

Научная специальность: 13.00.00 - педагогические науки. 